ISSN 1112-9867

\title{
AN EXAMINATION OF IRANIAN PENAL POLICIES TO DEAL WITH ADMINISTRATIVE AND ECONOMIC CORRUPTIONS, EMPHASIZING THE ISLAMIC PENAL CODE THAT'S BEEN ADOPTED IN 2013
}

\author{
A. Mozaffari* and M. Reza Rahmat \\ Department of Law, College of Law, Bandar Abbas Branch, Islamic Azad University, Bandar \\ Abbas, Iran
}

Published online: 16 July 2016

\begin{abstract}
Economic crime imposes very costs to society and because of its complexity detection and prosecution in difficult. So required some prehensive criminal policy. This research try to survey Iran's criminal policy about economic crimes with emphasis on new penal code, enacted in 2013. The results indicate that legislator has not been defined "economic crimes" term but is considered its instances according to articles 47, 36,109 of new penal code. Fighting against Economic Crimes must be including preventive measures and criminal reaction. Preventive measures has been coherent by dictating of United Nations Convention against Corruption (UNCAC) and fighting against Corruption internal code (2011) but Iran's legislator has not taken coherent policy to fighting economic crimes by criminal reaction . Although the new penal Code adopted some strict against this crimes but we couldn't see a coherent policy against its;
\end{abstract}

Keywords: criminal policy, economic crimes, economic corruption, Islamic Penal Code that's been adopted in 2013.

Author Correspondence, e-mail: entesharat.ban@gmail.com doi: http://dx.doi.org/10.4314/jfas.v8i2s.95 


\section{INTRODUCTION}

Economic is the beating pulse and the power of the community, so that every community may remain stable in terms of political relying on a powerful economic system. When economic corruption that is also known as white-collar crime occurs in the macro level it is a very dangerous threat to the general economy materials and it will undermine the stability and economic security and cause the huge damages on the body of economic system. Crime and corruption such as bribery, embezzlement, smuggling, money and banking crime, counterfeiting of currency and monetary instruments, money laundering and etc. welcome new forms, since such crimes are synchronized with technological developments and evolving industry fast, therefore the necessity of criminal law motion will get more prominent to keep pace with these developments. The criminal law should recognize economics corruption and define its constituent elements again. Most forms of administrative and economic corruption are new phenomena of our times. The reasons of their emergence are the development of industry, information technology, economic and trade relations and massive government intervention in the economy. The concept of economic crime has been discussed for at least a century and a half ago. However, a particular concept is taken of it according to the circumstances in each period. Economic crime, in the present concept was considered since the introduction of so-called "white collar criminals" by Sutherland an American criminologist in 1939. However, to achieve a single definition of economic crime has been associated with problems. According to Vito Tanzi, economic crime is an act which can be understood, but cannot be comprehend. In national and international legislation, economic crime is not clearly defined. But it has been sufficed to mention examples that are often agreed, such as money laundering, organized crime and corruption, soobvious features of economic crimes areconducted in organizing andforming these crimes.

\section{The relationship between economic crime and corruption}

Looking based on a criminal behavior, corruption has the most closely approximate to economic crime and the term economic corruption which is frequently used by researchers in the field of criminal law and the judicial system in recent years is due to the proximity of corruption and economic crime. Corruption is the use of legal status for the illegal advantages. This definition covers private sector and the public sector. In Black's Dictionary, corruption is considered as any behavior inconsistent with official duty or the rights of others which is taken place with the intent to obtain financial advantages. Magnusson mentioned some criteria such as commit motivation, standards, tools and instruments of crime for its 
accurate diagnosis of other crimes to assess the offender's criminal act without providing a definition of economic crime.

\section{Criminal law approach to the economic corruption in terms of the form and content}

Sometimes some laws even aimed at combating and dealing with economic crimes are the sources of economic corruption. Legislature cares to observe the correct principles of writing law at the time of adopting a law and expert attention to the practical aspects and its implications could prevent some abuses. In economic crimes discussions being regulated, being expressive, not being corrupt and availability of rules and regulations is extremely important. Thus it must be seen whether the law on economic crimes, particularly the Islamic Penal Code abided the legislation conditions in this field?

\section{Islamic Penal Code approach in terms of awareness of the law and the lack of inflation} of laws

Accumulation of rules is meant by inflation. Although criminal law is a necessity for society but indulge in this field will becoming a problem against criminal law. Accumulate and the multiplicity of laws will cause the lack of awareness of criminal law, the ambiguity in the law, difficulty in its implementation and ultimately the failure of the fight against crime.Regarding to administrative and financial affairs and economic activities of the country, the large number of criminal laws and regulations may lead to abusage of those who dominate the ways to escape from the law or abuse the ignorance of others rights. If a public interest is provided by law, legislators must guarantee that the beneficiaries of the new law are aware of their benefits to reduce the possibility of abuse in this way.

\section{Raising the cost of crime and proper criminal response}

Legislator must enhance the crime cost during the adoption of a criminal law in a way that the possible criminal prefers the crime harm to its interests from the beginning. Initially the criminal provisions of Iran, embezzlement and fraudulence perpetrators were not punished for paying bribes but with the adoption of the sanctions of the Penal Code in 1375, legislator determined punishable by imprisonment from six months to two years or up to 74 lashes for committing this crime under Article 592 of this law. But in order to encourage briber to announce or reporting the bribes pay they would be exempt from punishment. Legislator of Iran in order to raise the cost of crime to perpetrators of economic crimes has been appealed to the intensification and diversification punishment. While the multiple regulations such as the law against violators of economic system, intensify law and penal code has attempted to appoint severe regulations for perpetrators, in the meantime punishment has a great diversity in this case, so that the offenders with different mental and moral qualities will be forced in 
assessment of the profit and loss of the crime and expenditure of committing the of all aspects will increase. For perpetrators of such crimes there is a range of punishments, including death sentences, depriving freedom, financial penalties (confiscation of crime property, confiscation of property), lash, social exclusion, publishing, the deprivation of economic activity, temporary or permanent dismissal from government services etc. But it should be noted that those acts in the economic crimes have been criminalized that are not criminal in their nature and character.

\section{The responsibility of administrative authorities on charges of administrative corruption and deal with corruption}

Third chapter of administrative health law and deal with corruption approved in 1390 contain provisions that the administration officials and public as well as employees of these organizations individually are responsible to declare the administrative corruption. Article 13 of this law provides that all officials thatwere covered by this laware obliged to immediately report the crimes related to bribery, embezzlement, collusion in government transactions, obtaining percent in domestic trading, leveraging against the right and legal regulation, the involvement in government transactions in cases that they are legally banned, illegal acquisition of property, unauthorized use or illegal possession of government or public property or to waste them, deceive in government transactions, obtaining money or property that have been illegally gainedor applying to do it, considering a profit for themselves or others under any title, including commission rewards, remuneration or commission intransactions, auctions or call for bids and other economic offenses that are relating to corruption within the scope of their mission should be immediately reported to the judicial and administrative authorities that are dealing with crime and delinquency, otherwise they will be punished according to Article (606) of the Penal Code.

\section{Sentencing the administrative and economic corruptors}

Economic crime due to its characteristics (misuse of public funds, damage to public confidence about government activities and disrupt in the economic system) has many social obscenity and also it will directly destroy the government law in many cases, therefore the suppressive and severe punishment is preferred against these criminal action to have enough deterrent power and sufficient intimidation. In our criminal law, criminal response to economic crime covers a wide range of penalties.

\section{Complementary penalties for economic crimes}


The supplementary punishments are some executive guaranties that exist on the main penalties or apply beside them. These sanction or executive guaranties are different. They have been reckoned in Islamic penal code and Article 23 of the supplementary and complementary punishment.

\section{Dismissal of government and public services}

Considering that administrative corruption is committed by civil servants and public institutions, therefore temporary or permanent dismissal of government and public services is another commoncomplementary penalty for the perpetrators of these crimes. Thus, although offenders are deprived from their jobs, which is a heavy punishment, they would be away from organization for the specified time or even forever and the possibility of repeating the economic crime will be derived from them. In criminal provisions of Iran temporary or permanent dismissal of government and public services is one of the common penalties for offenders who are employed in public and government agencies. Permanent dismissal of public service in Article 19 of the Islamic Penal Code was as a prison sentence with grade 4 and it was beside 5 to 10 years imprisonment and a fine between 18 and 36 million tomans but a temporary suspension was conceivable as a supplementary punishment that has been expressed in the paragraph "d" of Article 23. Under article 1 of severe penalties law, if the perpetrators of bribery, embezzlement and fraud were public officials or public service officers they would be sentenced to dismissal of public service forever. It has been established in Note 2 of Article 1 about the fraud: "If public employees were the manager or higher level or equivalent to it, they would be sentenced to permanent dismissal of government service in addition to the punishment". It is also stipulated in Article 5 that if the embezzlement amount was excess of fifty thousand, the offender would be permanently dismissed of government services. For leadership or the formation of networks of bribery, embezzlement and fraud, permanent dismissal from government service is absolutely intended for the perpetrators as their punishment. And temporary suspension is predicted in some cases.

\section{Employment and economic deprivations}

Legislator in Article 23 of the Islamic Penal Code reckoned some deprivations as complementary or consequential punishment, which is the prohibition from employment, occupation, profession or certain work. In health promotion lawof office system and the fight against corruption that has been adopted in 1390, some employment and economic deprivations have been considered for economic criminals who commit corruption. They are kind of consequential punishments because of their necessity. Some of these deprivations in 
criminal law were scattered forecasted, but legislator coherently lists these deprivations and those who are subject to these deprivations for the first time. Some of these deprivations can be considered as administrative-disciplinary acts which are applicable just in the case of offenders who are dependent on the public and government agencies and those who are covered by the mentioned law.

\section{The economic crime and corruption sentence and challenges that are caused by Article 286 of the Islamic Penal Code}

In criminal policy of Iran, many economic crimes have been taken stringent security according to the doer intention against the state or a gang and the subject of crime changes to political and security figures from economic crime. In other words, economic crime that was offenses punishment at the beginning will change to Deserving Legal Punishment. The prevailing clue is that the economic crime was interpreted as corruption on earth and therefore it referred to Deserving Legal Punishment crimes. One of the most important of these punishments is death (hanging) which will be discussed about it in accordance with the provisions of the Islamic Penal Code. Various scattered rules that have been adopted in the field of economic crime are some instances of criminal activities in these fieldsthat are equivalent to corruption on earth which is punishable by death.

\section{Collapse of economic crimes penalty}

Lapse of time in Penal Matters is a time passing that from a legal point of view, after that period complaint declarations or prosecution and investigations of public fights and finally punishment would not be possible. As the Article 173 of the Code of Criminal Procedure adopted in1378 stated about lapse of time in Penal Matters: "In crimes that its legal punishment is a deterrent punishment or security measures and training, and the prosecution request has not been done from the date of the crime until the expiration of the deadline, or it has not been ended with sentencing from the date of the first prosecution to the expiration of deadlines, prosecution will be suspended". Following the adoption of this legal Article of the courts that which one of the criminal cases will be covered by this provision, incoherence of votes appeared and at least 6 votes about uniformity of treatment from the Supreme Court were issued between the years 1386 to 1387 . However this article doesn't mention the economic crimes and just legal sanctions, limits and diya have been excluded from lapse of time.

\section{CONCLUSION}

This study was intended to investigate Iran's penal policy to deal with administrative and economic corruption and in this regard, it has a greater emphasis on the criminal provisions 
that have been adopted recently specially the Islamic Penal Code that has been adopted in 1392. The research results indicate that:

1. Those financial crimes which in legal literature of officials have been widely used as corruption or administrative corruption and are the subject of this study, are entered into the category of "economic crimes" in the Islamic Penal Code adopted in 1392 and they have specific provisions in some cases, but legislator has established the first foundation stone on ambiguity in the fight against economic. The reason for this ambiguity is that economic crimes are not recognized and although in Article 47 of the Penal Code, the legislator has not clearly stating the crime that are included in this category or giving a criteria for its recognition, he has used the term "economic crimes" and put an important sentence on it. Economic crime with crime issue cannot be postponed or suspended. The fact is that the usage of the term "economic crimes" is vague and it should be interpreted. Legal doctrine cannot give a single definition in this context and this issue is hotly disputed in legal literature. So law in this context is ambiguous and vague law will also cause corruption. The author's interpretation is that legislator in Article 36 and also paragraph d of Article 109 of the Islamic Penal Code has reckoned these crimes which include thirteen crimes that have been mentioned in the provisions and legislator also added fraud to this list under Article 109. Therefore instances of economic crime are those fourteen crimes. When legislator have absolutely used the term economic crimes in paragraph $\mathrm{C}$ of Article 47, he thought that he has determined the crimes of this category. With this narrow interpretation, offenders of major crimes such as illegally property acquisition, forgery, utilizing of forged and stolen documents with any level of crime issue are not covered by exclusion from deferred sentencing and suspension of punishment, unless they have been be deprived of this right because of grading in penalties.

2. Considering the provisions of the three articles 35, 47 and 109 of the Penal Code can be said that legislator has categorized the economic crime into three minor crimes, medium and major crimes in terms of the monetary. The minor economic crimes are those that their crime theme is less than a hundred million riyals. The medium economic crimes are crimes that their crime theme is between one hundred million to one billion riyals and finally major economic crimes are crimes that their crime theme is more than one billion riyals. his category partly helps us to use them in other scattered criminal provisions on criminalization of economic crimes. For example, the law on punishment for violators of economic system of country, the Penal Code of 
hoarders, etc. that legislators has used "major", "macro" without giving a criteria or a definition of these terms and has applied specific provisions on the perpetrators of such crimes. So the criterion of being major or macro is having theme crime more than one billion riyals. A major drawback of this interpretation is that if it was to the detriment of the accused, is would not be acceptable because it's a relaxed interpretation.

3. The Islamic Penal Code legislator has tried to guarantee that the finality and certainty of penalty for medium and major economic crimes on offenders is a deterrent solution, therefore he was strict on some punishment exemption and reduction strategies of economic offenders. For example, in Article 47, medium and macroeconomic criminals were deprived from 2 exemption ways of punishment, including postponed sentences and suspension of penalty. Legislator has also added subordinated punishes to the punishment of macroeconomic offenders. These offenders must be published through national and local media and the press by publication of their sentences. As well as pursuant to section d of Article 109 of the Islamic Penal Code, macro-economic offenders would not be included in the lapse of time prosecution and implementation of punishment. Thus the penal policy will appear to deal with economic crimes severely. It should be noted that this strict policy about certainty of the punishment of economic offenders has not been followed consistently and continuously. Still there are some exemption and reduction strategies for it. The new utilities of annulled or reduced punishment such as conditional release, parole and acceptance of repentance are some loopholes of all or part of the punishment. Regarding to conditional release there is no constraint to make exceptions on economic crimes. As well as the economic crime offenders are described as corruption on earth because of their major crimes and having the other conditions, thus death punishment have been considered for their crimes, but they can repent and ask their pardon from leadership by the repentance solution that the legislator has provided in Article 114 of the Islamic Penal Code. Also for the medium and major economic criminals who have been sentenced, repent can also be used as an extenuating strategy of punishment. Some micro-economic offenders that have been sentenced to seventh and eighth grade penalties can use the repent solution to escape of their punishment. 


\section{REFERENCES}

1. Assyrian, Mohammed, criminal procedure, Tehran Allameh Tabatabai University Publications Center, twelfth edition, the summer of 2007.

2. Aghazadeh, AR; check the smuggling analytical criminal policy towards Iran, printing, publishing Arian, Tehran 2005.

3. Beccaria, Caesar. Crime and punishment essay, translated by Mohammad Ali ardebili, Tehran, published in 1995.

4. Pradl, Jean. Criminal history of ideas, translator, Ali Hussain NajafiAbrndabady, the publisher, 2002.

5. Treaty, Zia, crimes against the security of public welfare, Fifth Edition, Tehran: Publication of 2002.

6. Tavasolizade, Touran, the prevention of economic crime, Tehran: Woods, 2012.

7. Langroodijafari, MJ; terminology rights, Thirteenth Edition, library treasure of knowledge, in Tehran in 2003.

8. Dadkhdayy, Leila. Administrative and financial corruption criminal policy to deal with it: based on the UN Convention against corruption. Tehran: Legal Foundation in 2011.

9. Rayjyan Main, M., protection of victims, Tehran, publishing of Justice, 8713.

10. Rubaie, Ali. Long live the corruption, Tehran: Publication of the Ministry of Culture and Islamic Guidance: 2004.

11. Dana, Fariborz, social pathologies in Iran, Iranian Sociological Association, abstracts arguments in the financial-economic crimes, printing, Tehran: Agah, 2004.

12. Zeraat, Abbas, a brief description of the Penal Code (adopted in 2013), Tehran, Phoenix, 2014 ,

13. Sheikh al-Abbas, "The results of criminology position on developments in the Iranian criminal legal system", Proceedings of Criminal Sciences (Proceedings in honor of professor doctor Mohammed Ashouri), first edition, the publisher, Tehran 2004.

14. Salahi, javid, penology and new concepts, Tehran: Publication of 2007.

15. Abbaszadegan, Mohammad, Corruption, Tehran: Cultural Research Bureau, 2004.

16. Shmavy, SaadEddin Mohammed. A review of economic crime in Arabic, translated by Hussein Nasrallah and Sayyed Isa Hussaini, Tehran police release, 2007.

17. alimiri, Mustafa. Inspection in the mirror law, proceedings of the first meeting of the monitoring and inspection of Iran, Tehran: Publication GIO, 1997.

18. Friedman, Lawrence, deterrence, translation Ayatollah AsgharTalebiAranGhahremanpour, printing, Mashhad, Razavi Publications, 2007. 
19. Gsn, Raymond. Mqdmh $\neg$ Ay on criminology, doctor Mehdi who need translation, printing, Tehran: Translator, 2004.

20. Mohammadi, Hamid, recording, confiscation and return of property, Tehran, The Treasure of Knowledge. 2011.

21. Mahdipour, Azam, differential criminal policy in the field of economic crime, Tehran, Nshrmyzan, first edition, 2011.

22. Mir Mohammad Sadeghi, Hossein; international criminal law (Proceedings), printing, Tehran, published in 1998.

23. Mir Mohammad Sadeghi, Hossein; crimes against public safety, second edition, published in Tehran, 2002.

24. Nourzad, M, economic crime in the penal code in Iran, Tehran: forest, immortal, 2010.

25. Firuznoruzi, the. General criminal justice: punishment, Tehran: Publication of 2011.

26. Walid Saleh, specific criminal law, C 2, Third Edition, published by Technology, Tehran,2003

27. Ardabil, Ali, "the philosophy of procrastination penalty", the newspaper supported, No. 2531, date 2012 .

28. Ardeshir, Mansour. "Privatization in Higher Education", Journal of parliament and strategy, No. 55, Summer 2007.

29. Aqtrah jurisdiction of economic crimes, journal of our time, 2001.

30. Jeremy Pope, "parliament and legislation against corruption", translation M. cry, parliament and strategy magazine, Issue 52, Autumn 2006.

31. Habibzade Mohammad, pathology Iranian criminal justice system, Humanities and Social Sciences, University of Shiraz, 2004, \& Page 145

32. HabybZadh, M, NajafiAbrndabady, Ali Hussein, K. Sheriff, "criminal inflation, causes and consequences", Journal of Teacher, Vol. 5, No. 4, Winter 2001.

33. Hosseini, Seyed Hussein, "comparative perspective on how the reflection of bribery in the legal systems of France, Italy, Switzerland and China," Journal of Law, No. 6ᄀ, 2004.

34. Hosseini, Seyed Hussein and MotevalizadehNaini, Nafisa. "The Labeling Theory", Journal of the Faculty of Law and Political Science. Forty-second year. No. 4 Winter 2012.

35. Dadkhdayy, Layla, "the concept of economic crime and its evolution", Journal of excellence Rights, Issue 6, 2010.

36. Rustaeemehrangiz., "Evaluation of criminal involvement in economic crimes", Journal Detective, Volume II, Issue 7, Summer 2009. 
37. Mahmoudi junk, Fairuz. Security and insecurity from the perspective of criminal policy, issue legal opinions, Number 8, 2004.

38. Shams, Mohammad Ebrahim. tavasoliZadeh resort, Turan, "situational prevention of economic crimes", Journal of Law Faculty of Law and Political Science, Volume 41, Number 4, Winter 2011.

\section{How to cite this article:}

Mozaffari A, Reza Rahmat M. An examination of iranian penal policies to deal with administrative and economic corruptions, emphasizing the islamic penal code that's been adopted in 2013. J. Fundam. Appl. Sci., 2016, 8(2S), 1595-1605. 